\title{
Recent advances in the treatment of age-related macular degeneration
}

Loss of central vision with age-related macular degeneration (ARMD) is a devastating reality for $8 \%$ of adults aged over 65 years in the UK, ${ }^{1}$ but new therapies with the potential to halt and improve visual loss have emerged. As a result, the NHS faces some difficult choices in terms of provision of and access to treatments.

ARMD is thought to be a group of genetically- and environmentallydetermined retinal degenerative diseases: in ARMD there is an age-related dysfunction of the retinal pigment epithelial cells, which are essential for photoreceptor metabolism and removal of waste products. Dysfunctional cells accumulate undigested waste, which is clinically evident as focal yellow subretinal clumps, termed drusen. Drusen are the herald of ARMD, and large or numerous drusen are poor prognostic factors for future visual loss. ${ }^{2}$ The disruption of photoreceptor metabolism eventually causes areas of retinal atrophy: the macula, the 'high definition' central point of the retina with the highest density of photoreceptors, is consequently more susceptible to this progressive dysfunction.

In the majority of patients, ARMD occurs as atrophic or 'dry' macular degeneration. This is a relatively slow process, and at the present time there is no effective treatment. In the remaining patients with 'wet' or neovascular disease there is aberrant growth of choroidal blood vessels beneath the dysfunctional retina: haemorrhage and oedema from these neovascular membranes causes sudden central visual loss. Retinal angiography is needed to identify and classify the membranes as 'classic' welldefined lesions or amorphous 'occult' membranes, as the classification has an impact on the treatments available. A current estimate of the incidence of wet ARMD in the UK is around 21000 new cases each year. ${ }^{3}$

Patients with ARMD who need referral to ophthalmic services present to their primary care provider or optometrist with gradual visual loss, or more urgently with sudden central visual loss. The Royal College of Ophthalmologists recommends that this 'urgent' group should undergo retinal angiography and assessment for possible treatment within 2 weeks of visual loss. ${ }^{3,4}$ To improve the efficiency of the patient journey, and in this era of practice-based commissioning, there is an argument that optometrists should make direct referrals to ophthalmology services where necessary. Optometrists also play a vital screening role in the detection of the asymptomatic agerelated maculopathy (drusen and focal retinal pigment epithelial changes) precedent to symptomatic ARMD.

Detection of the earlier changes is important as there is evidence that intervention at this stage can alter progression; for example, patients can be advised to stop smoking. Although ARMD has a multifactorial aetiology, with a recently discovered HTRA1 gene polymorphism ${ }^{5}$ (and no doubt more genetic associations to come), smoking is the significant avoidable risk factor for developing ARMD:2 smokers are 3.6 times more likely to develop ARMD than those who have never smoked.

The Age-Related Eye Disease Study (AREDS) demonstrated that a combination of high doses of vitamins $C$ and $E$, betacarotene, and zinc reduces the risk of second-eye progression in patients with significant visual loss from wet ARMD. ${ }^{6}$ Beta-carotene is contraindicated in smokers because of the increased risk of small cell lung cancer, ${ }^{6}$ while long-term vitamin $\mathrm{E}$ should be used with caution in patients with cardiovascular disease because of a possible increased risk of heart failure. ${ }^{7} \mathrm{~A}$ number of formulations are available with or without these contentious ingredients; as yet there is no proven benefit for the wider group of patients with ARMD, but all patients should be advised to eat a balanced diet.

As there is no known effective treatment for dry ARMD, adequate social support and visual rehabilitation is essential. For example, patients can be referred by the ophthalmologist to low visual aid clinics, for training in the use of magnifying glasses or eccentric viewing techniques. If necessary, patients with ARMD can also be formally registered as visually impaired. Ancillary organisations, such as the Royal National Institute for the Blind, Macular Disease Society, and Sight Savers, can also provide invaluable support for patients with ARMD. Depression rates among this vulnerable group are as high as $30 \%$, and severity of depression is not always linked to severity of visual loss. ${ }^{8}$

Interventional research has centred on wet $A R M D$ and anti-angiogenesis either through direct obliteration of neovascular membranes or inhibition of pro-angiogenic cytokines, such as vascular endothelial growth factor (VEGF).

Photodynamic therapy has been recommended by the National Institute for Clinical Excellence (NICE) for the treatment of predominantly 'classic' wet ARMD in patients with visual acuities no worse than 6/60: verteporforin (Visudyne ${ }^{\circledR}$, Novartis) is injected intravenously, binds to the subretinal neovascular membrane, and is laser activated, which releases destructive free radicals and results in significantly reduced visual loss progression. ${ }^{9}$ There are an estimated 7000 patients eligible for treatment with verteporforin based on the NICE criteria, ${ }^{4}$ which has recently been broadened in some primary care trusts. Photodynamic therapy focuses on the membrane rather than the underlying angiogenic molecular environment, so there is reduction in efficacy over time.

The emergent anti-angiogenic pharmacotherapies deal with the molecular environment, specifically VEGF, so the potential advantage over photodynamic therapy is broader efficacy in a number of lesion subtypes and less destruction of 'normal' tissue. These treatments all require intraocular injections with a low associated risk of intraocular infection or haemorrhage. Despite the fact that multiple treatments are often required, patient-based surveys have consistently shown that these invasive treatments confer an improved quality of life. ${ }^{10}$

Pegaptanib sodium (Macugen ${ }^{\circledast}$, Pfizer) significantly reduces the progression to 
severe visual loss in wet ARMD by $50 \%$ at 1 year. ${ }^{11}$ Macugen is under NICE evaluation and is available on a trial basis at selected UK centres. Ranibizumab (Lucentis ${ }^{\circledR}$, Novartis), which is also under NICE evaluation, has been shown to prevent visual loss in $95 \%$ of patients and, remarkably, improves visual acuity in 35\%. ${ }^{12}$ Bevacizumab (Avastin ${ }^{\circledast}$, Roche), previously approved for the treatment of metastatic colorectal carcinoma, has been used increasingly since 2005 in the treatment of wet ARMD, but is not licensed for intraocular use. The progenitor to Lucentis ${ }^{\circledR}$, and marketed by the same company in the US (Genetech), the larger Avastin molecule, was thought unlikely to cross retinal layers, but has been shown to cross diseased retinae with encouraging results and low rate of adverse events. ${ }^{13}$

Recent estimates suggest that there may be 21000 new cases of wet ARMD eligible for these new drugs each year, compared with 7000 patients eligible for photodynamic therapy. ${ }^{4}$ The significant advantage of Avastin is its low cost: $£ 3$ compared to over $£ 1000$ per treatment for the specificallydesigned Lucentis $^{\circledast}$. However, the implications for the NHS are significant, not only in terms of the financial cost of the drug, but also trained personnel and infrastructure. A recent cost analysis of ARMD therapies estimated the total 2-year costs for treatment at approximately $€ 1400 / £ 1000$ for Avastin ${ }^{\circledast}, € 7600 / £ 5600$ for Visudyne $^{\circledast}$, €18 600/£13 900 for Macugen ${ }^{\circledast}$, and $€ 45$ 900/£34 200 for Lucentis ${ }^{\circledR}$. ${ }^{10}$

Anti-angiogenic steroids such as anecortave acetate (Retaane ${ }^{\circledast}$, Alcon) and squalamine lactate (Evizon ${ }^{\text {TM }}$, Genaera Corporation) have also been shown to reduce neovascularisation. ${ }^{14,15}$ Further studies are underway.

NICE aimed to complete its consultation on Lucentis ${ }^{\circledast}$ and Macugen ${ }^{\circledast}$ by early 2008 , but has no plans to evaluate Avastin ${ }^{\oplus}$. The presumed reason for this oversight has been the accepted dogma that NICE is unable to evaluate 'off-label' medicines, as they do not receive the relevant drug referrals from the Department of Health and the Medicines and Healthcare products Regulatory Agency. A Department of Health spokesperson recently stated that their 'hands were tied' with regards to referring Avastin ${ }^{\circledast}$ to NICE for evaluation. ${ }^{16}$ This is not supported by published guidelines on NICE recommendations which state that 'use outside a licensed indication may be recommended'. ${ }^{17}$ Genetech has expressed worries regarding the sterility of Avastin ${ }^{\circledast}$ packaging as the reason why they are not applying for a license for the intraocular use of the much cheaper drug, ${ }^{18}$ despite strong support for the intra-ocular use of Avastin ${ }^{\circledast}$ from the American Academy of Ophthalmology. ${ }^{19}$ As such, clinicians wishing to use Avastin are faced with ethical questions surrounding off-label drug prescription and conventional evidencebased drug consultation. There is now growing pressure on NICE from professional and patient lobbies to evaluate Avastin $^{\circledast}$ for wet ARMD.

In the short-term future, treatments targeting ageing by encouraging the dispersal of accumulating waste products show promise, and retinal stem cell transplants provide hope for millions of patients blinded by diseases such as macular degeneration. Viral vector gene therapy also holds great potential.

The challenge ahead lies in the health economics of access to these drugs and the other emerging treatments, but the future is indeed brighter for our patients.

\section{Ameenat Lola Solebo,}

Specialist Trainee in Ophthalmology, St George's Hospital, Moorfields NHS Trust, London

\section{Romesh I Angunawela,}

Research Fellow, Kings College London Department of Ophthalmology, The Rayne Institute, St Thomas' Hospital, London

\section{Samipa Dasgupta,}

GP, Redbridge Primary Care Trust

\section{John Marshall,}

Professor of Ophthalmology, Kings College London Department of Ophthalmology, The Rayne Institute, St Thomas' Hospital, London

\section{REFERENCES}

1. Bonastre J, Le Pen C, Anderson P, et al. The epidemiology, economics and quality of life burden of age-related macular degeneration in France, Germany, Italy and the United Kingdom. Eur J Health Econ 2002; 3(2): 94-102.

2. Tomany SC, Wang JJ, Van Leeuwen R, et al. Risk factors for incident age-related macular degeneration: pooled findings from 3 continents. Ophthalmology 2004; 111(7): 1280-1287.

3. Fletcher A, Donoghue M, Owen C. Low vision services for people with age related macular degeneration in the UK: $a$ review of service need and provision. London: London School of Hygiene and Tropical Medicine. (Submitted to the Macular Disease Society, June 2001).

4. Amoaku WMK. AMD interim guidelines: The Royal College of Ophthalmologists interim recomendations for the management of patients with age related macular degeneration (AMD). London: RCO, 2006.

5. Yang Z, Camp NJ, Sun H, et al. A variant of the HTRAl gene increases susceptibility to age-related macular degeneration. Science 2006; 314: 992-993.

6. Age-Related Eye Disease Study Research Group. A randomized, placebo-controlled, clinical trial of highdose supplementation with vitamins $\mathrm{C}$ and $\mathrm{E}$, beta carotene, and zinc for age-related macular degeneration and vision loss: AREDS report no. 8. Arch Ophthalmol 2001; 119(10): 1417-1436.

7 Lonn E, Bosch J, Yusuf S, et al. Effects of long-term vitamin E supplementation on cardiovascular events and cancer: a randomised controlled trial. JAMA 2005; 293(11): 1338-1347.

8 Casten A, Robin J, Rovner, BW, Tasman W. Age-related macular degeneration and depression: a review of recent research. Curr Opin Ophthalmology 2004; 15(3): 181-183.

9. Wormald R, Evans I, Smeeth L, Henshaw K. Photodynamic therapy for neovascular age-related macular degeneration. Cochrane Database Syst Rev 2007; 3: CD002030.

10. Brown GC, Brown MM, Brown HC, et al. A value-based medicine comparison of interventions for subfoveal neovascular macular degeneration. Ophthalmology 2007; 114(6): 1170-1178

11. Kourlas H, Schiller DS. Pegaptanib sodium for the treatment of neovascular age-related macular degeneration: a review. Clin Ther 2006; 28(1):36-44.

12. Rosenfeld PJ, Brown DM, Heier JS, et al. Ranibizumab for neovascular age-related macular degeneration. $N$ Engl J Med 2006; 355(14): 1419-1431.

13. Wu L, Martínez-Castellanos MA, Quiroz-Mercado H, et al. Twelve-month safety of intravitreal injections of bevacizumab (Avastin ${ }^{\circledR}$ ): results of the Pan-American Collaborative Retina Study Group (PACORES). Graefes Arch Clin Exp Ophthalmol 2008; 246(1): 81-87.

14. Slakter JS, Bochow TW, D'Amico DJ, et al. Anecortave acetate (15 milligrams) versus photodynamic therapy fo treatment of subfoveal neovascularization in age-related macular degeneration. Ophthalmology 2006; 113(1):3-13.

15. Connolly B, Desai A, Garcia CA, et al. Squalamine lactate for exudative age-related macular degeneration. Ophthalmol Clin North Am 2006; 19(3): 381-91, vi.

16. Bosely S. Drug firm blocks cheap blindness cure. Guardian 2006; 17 June:

http://www.guardian.co.uk/society/2006/jun/17/health. medicineandhealth (accessed 9 Apr 2008).

17. National Institute of Clinical Excellence. Creating guideline recommendations. Section 11.2.4 http://www.nice.org.uk/niceMedia/pdf/2006Guidelines ManualChapter11.pdf (accessed 9 Apr 2008).

18. Desmond-Hellman S. Letter to physicians. http://www.gene.com/gene/features/avastin/letter-tophysicians.html (accessed 9 Apr 2008).

19. American Academy of Ophthalmology. American Academy of Ophthalmology supports coverage of ophthalmologists' use of intravitreal bevacizumab. http://www.aao.org/newsroom/release/20060420.cfm (accessed 10 Apr 2008).

ADDRESS FOR CORRESPONDENCE:

AL Solebo,

Moorfields NHS Trust, St Georges Hospital, Ophthalmology, Blackshaw Road, Tooting, London, SW17 OQT. Lola.Solebo@moorfields.nhs.uk 